\title{
Dynamic systems as tools for analysing human judgement
}

\author{
Joachim Funke \\ Heidelberg University, Germany
}

\begin{abstract}
With the advent of computers in the experimental labs, dynamic systems have become a new tool for research on problem solving and decision making. A short review of this research is given and the main features of these systems (connectivity and dynamics) are illustrated. To allow systematic approaches to the influential variables in this area, two formal frameworks (linear structural equations and finite state automata) are presented. Besides the formal background, the article sets out how the task demands of system identification and system control can be realised in these environments, and how psychometrically acceptable dependent variables can be derived.
\end{abstract}

The use of computer-simulated scenarios in problem-solving research has become increasingly popular during the last 25 years (for a representative collection of papers see, e.g., the two editions from Sternberg \& Frensch, 1991, and Frensch \& Funke, 1995). This new approach to problem solving seems attractive for several reasons. In contrast to static problems, computer-simulated scenarios provide a unique opportunity to study human problem-solving and decision-making behaviour when the task environment and subjects' actions change concurrently. Subjects can manipulate a specific scenario via a number of input variables (typically ranging from 2 to 20, and in some exceptional instances even up to 2000), and they observe the system's state changes in a number of output variables. In exploring and/or controlling a system, subjects have to continuously acquire and use knowledge about the internal structure of the system.

Correspondence should be addressed to Dr Joachim Funke, Department of Psychology, Heidelberg University, Hauptstr., 47-51, D-69117 Heidelberg, Germany. Email: Joachim.Funke@urz.uni-heidelberg.de

This research was partly supported by a grant from the Commission of the European Community (TSER Project "NatCCC-PS", contract SOE2-CT98-2042). I wish to thank Dominica Osiecka for valuable help with translation. Thanks are due to Georgios Rigas and two anonymous reviewers for helpful comments. Finally, Nigel Harvey gave really constructive ideas on how to improve the paper-thank you! 
Research on dynamic systems was motivated partly because traditional IQ tests turned out to be weak predictors in non-academic environments (see Rigas \& Brehmer, 1999, p. 45). According to their proponents, computer-simulated "microworlds" seem to possess what is called "ecological validity". Simulations of (simplified) industrial production (e.g., Moray, Lootsteen, \& Pajak, 1986), medical systems (e.g., Gardner \& Berry, 1995), or political processes (e.g., Dörner, 1987) have the appeal of bringing "real-world tasks" to the laboratory. Brehmer and Dörner (1993) argue that these scenarios escape both the narrow straits of the laboratory and the deep blue sea of the field study, because scenarios allow for a high degree of fidelity with respect to reality and at the same time allow systematic control of influential factors.

These and other arguments have stimulated the use of a great diversity of dynamic systems as experimental task environments, each of which is designed to relate to a different aspect of "reality". The problem, however, is that such vastly different experimental tasks and, hence, the results of experiments using these tasks, are very difficult to compare. In particular, it becomes unclear whether one should attribute experimental findings to the experimenter's manipulation or to the peculiarities of the task employed. Most systems do not differ only with respect to surface features (i.e., the semantics implied by the labelling of their input and output variables) which we know to have strong influences on problem-solving behaviour in both static (e.g., Blessing \& Ross, 1996; Hesse, Kauer, \& Spies, 1997; Kotovsky \& Fallside, 1989; Novick, 1988; Wagenaar, Keren, \& Lichtenstein, 1988) and dynamic tasks (e.g., Hesse, 1982; Luc, Marescaux, \& Karnas, 1989; Preußler, 1997; Putz-Osterloh, 1993). Equally important, for most systems it is not clear how to compare them with respect to the underlying formal structure.

There are two possible solutions to the latter problem. One possibility is to define a set of formal dynamic system characteristics and use this set to systematically compare the tasks used in various experiments (e.g., Funke, 1990). Such an analysis will at least give a rough idea of whether or not two dynamic tasks could yield comparable results. The other possibility is to derive different dynamic task environments from the same formal background. The formal homogeneity of different task environments facilitates comparisons between experiments and increases the chances of discovering effects that are not just "local". In the following sections I will illustrate this second solution.

Before going into detail, let me add that dynamic systems are not only useful and necessary as task environments. With even more emphasis I would argue that we also need dynamic systems on the side of the theories (for example, van Gelder, 1998). The world is dynamic and we have to adapt continually. Static theories do not provide adequate explanations for how we cope in most of life's activities. But that is another story - the current paper is primarily about tools and less about theories. 
The plan of this paper is first to give a short review of the history of complex problem solving (CPS), second to elaborate in more detail the important features of a complex problem, third to demonstrate the use of two formal frameworks (linear structural equation systems and the theory of finite state automata) for constructing dynamic decision situations, and fourth to show what task demands result from such situations and what measures could be derived from the subjects' interactions with these scenarios. A final conclusion will also mention some of the unsolved problems of this approach.

\section{SHORT HISTORY OF COMPLEX PROBLEM SOLVING (CPS)}

According to Buchner (1995) the history of CPS has two roots in the European countries, one resulting from Donald Broadbent's research on different memory systems (Berry \& Broadbent, 1984, 1988; Broadbent, 1977; Broadbent \& Aston, 1978; Broadbent, Fitzgerald, \& Broadbent, 1986; Hayes \& Broadbent, 1988), the other from Dietrich Dörner's research on the structure of intelligent behaviour (Dörner, 1987; Dörner, Kreuzig, Reither, \& Stäudel, 1983; Dörner \& Wearing, 1995). The first was dedicated to the experimental approach and therefore used very simple dynamic tasks (e.g., a simple transportation system or a simple sugar factory); the second one was a kind of exploratory work using a dynamic system with more than 2000 variables (for the simulated town called "Lohhausen"). Broadbent's work has led to the elaboration of explicit and implicit modes of learning and could be classified as one of the early dissociation studies which have been conducted many times in many different ways (for a review see Berry \& Broadbent, 1995). ${ }^{1}$ Dörner's work has led to an intensive discussion about the shortcomings of current IQ testing and to an action-theoretical analysis of acting in complex environments (Dörner, 1986, 1996; Dörner \& Kreuzig, 1983; Dörner, Schaub, \& Strohschneider, 1999). In the remaining part of the paper, I will concentrate on the latter issues, because from a human judgement point of view these topics seem to be more fruitful than elaborating on the explicit/implicit distinction (which has been well documented, for example, in the handbook edited by Stadler \& Frensch, 1998).

In the early work of Dörner and his associates, disappointment was expressed with the low predictive power of traditional IQ testing for problem solving in everyday situations. Instead of using tasks that might be seen as rather academic, Dörner proposed an alternative approach: constructing complex everyday problems as simulated scenarios with which subjects had to interact under controlled conditions in the lab (see Brehmer \& Dörner, 1993; Brehmer, Leplat, \&

\footnotetext{
${ }^{1}$ Note that there are reasons not to subsume Broadbent's work under the label "implicit/ explicit”, see for example Frensch (1998, p. 12).
} 
Rasmussen, 1991). Subjects acting in these scenarios did indeed face a lot more tasks than in the IQ tests: (a) the complexity of the situation and (b) the connectivity between a huge number of variables forced the actors to reduce a large amount of information and anticipate side effects; (c) the dynamic nature of the problem situation required the prediction of future developments (a kind of planning) as well as long-term control of decision effects; (d) the intransparency (opaqueness) of the scenarios required the systematic collection of information; (e) the existence of multiple goals (polytely) required the careful elaboration of priorities and a balance between contradicting, conflicting goals.

If one compares this description of the CPS framework with that of the "naturalistic decision making" (NDM) approach, a lot of similarities emerge. According to Zsambok (1997, p. 4), NDM concentrates on the way people use their experience to make decisions in field settings. Key contextual factors are seen as (a) the existence of ill-structured problems, (b) in uncertain, dynamic environments, (c) with shifting, ill-defined, or competing goals, and (d) the existence of action and feedback loops, (e) time stress, (f) high stakes, (g) multiple players, and $(\mathrm{h})$ the presence of organisational goals and norms. From this characterisation of the two approaches, CPS and NDM, it follows that there exist commonalities as well as differences between them.

The commonalities between CPS and NDM can be found in their concentration on real-life rather than artificial tasks. The main reason for this shift is validity. Real-life tasks are characterised as ill-structured and dynamic, requiring multi-step decisions within a multi-goal situation. The differences between CPS and NDM can be found in their focus of research. Whereas NDM is directed to decision making by experts within their domains of expertise, CPS has a focus on novices and their action regulation in general, therefore including, for example, an analysis of emotional aspects as part of this regulation process. Decision making, from a CPS point of view, is only one instrument among others for action regulation. Differences between NDM and CPS can also be found with respect to their methods. Whereas NDM researchers usually observe decision makers in real life, CPS researchers analyse subjects' behaviour when interacting with microworlds. In contrast to classical psychological experiments, in which reality is mapped according to the principle of reduction, many microworld studies use a mapping according to the principle of condensation (for deeper discussion of reduction versus condensation, see Dörner, 1992).

However, these differences between the two approaches are minor ones. As Klein (1997) points out, NDM research does not exclude the study of novices, and as Sternberg (1995) put it, even novices might be experts for life in general. To summarise: CPS and NDM have in common their concentration on tasks and scenarios with a high degree of fidelity ${ }^{2}$ with respect to real life. Their differences seem to me to be of minor importance.

\footnotetext{
${ }^{2}$ For the concept of fidelity, especially with respect to transfer of training, see Hays and Singer (1989).
} 


\section{FEATURES OF CPS}

Before dealing with two formal frameworks more precisely, I will first discuss the main features of complex problems. In the previous section describing the early phases of CPS research, the following five typical qualities of a CPS scenario were mentioned (see Dörner, 1980; Dörner et al., 1983): (a) complexity, (b) connectivity, (c) dynamics, (d) intransparency (opaqueness), and (e) polytely (i.e., a problem situation having many goals at the same time). This list remained more or less unchanged in the later studies; at most the former controversy about a taxonomy of systems and tasks (see Funke, 1990; Hussy, 1984, p. 122f; Strohschneider, 1991) dealt with this question in more detail. ${ }^{3}$ A closer examination of the five CPS features just listed allows three conclusions:

First, the (a) complexity and (b) connectivity features are hardly to be distinguished. Considering the unclear definition of complexity (often understood as "number of variables with a system"; for a critique of this simple definition of complexity see Funke, 1984; Kotkamp, 1999, p. 27; Strauß, 1993, p. 38; Wallach, 1998, p. 130), I suggest we concentrate on the more comprehensible term "connectivity", understood as dependency between two or more variables. Connectivity is an important feature of complex systems (see Casti, 1979) and requires a subject to figure out the connections between the variables; that is, to construct a causal model of the system under consideration.

Second, the feature (c) dynamics is a second important characteristic of a CPS system, making it clearly distinct from a static problem, which does not change its state over time. Whereas the aspect of connectivity is related to the structural relationships within a system, the aspect of dynamics is related to processes within a system. Therefore, a subject has to find out how the system develops or changes over time and what the short- and long-term effects of specific interventions are.

Third, the features (d) intransparency and (e) polytely (multiple goals) are not aspects inherent in a system, but refer to certain decisions of the experimenter, namely, how much information about the system will be given to a subject and what goals the subject is instructed to follow. Because these two features could also be used in static experimental set-ups, they are not specific to systems used in CPS research. One can say that these two features are often part of a CPS presentation to a subject, but they are not features of the computer-simulated system, like connectivity or dynamics.

To summarise: in CPS research, tasks are used which consist of two specific, distinctive features, namely connectivity and dynamics. Both attributes need a computer program for their realisation, and cannot be realised by a paperand-pencil approach.

\footnotetext{
${ }^{3}$ From today's point of view, there is to add to this controversy that at least the distinction between person and situation characteristics has found broader consensus (see Kersting, 1999, p. 10; Strauß, 1993, p. 29).
} 
But what type of computer program is needed? If one looks through those produced up to now for CPS research purposes (for reviews see Funke, 1988, 1991, 1995), there exists a broad number of systems, each of them programmed in a unique manner, not easy to change for experimental purposes, and not at all comparable to other programs. This lack of comparison leads to a heterogeneity of results and to a situation where no clear-cut conclusions can be drawn from the experimental work.

As already mentioned, one escape from this situation may come from the use of formal frameworks, which allow us to construct systems systematically with a specified degree of connectivity and dynamics. So, the goals of this "psychometric approach" to CPS are (1) to represent the important features of a complex system in order to realise really complex problems, (2) to allow for the systematic construction and variation of systems in order to reveal the influential factors that determine the subject's difficulty in handling the system, (3) to enhance the comparability of systems by using the formalism as a common framework for description and comparison, and (4) to allow for a straightforward derivation of measures in order to produce reliable indicators.

In a certain sense, one can see this proposal as a kind of "Ebbinghaus approach" to CPS (giving priority to carefully constructed test material and, to properly defined measures at the expense of face validity), compared to the "Bartlett approach" to CPS (giving emphasis to the ecological validity of the simulated reality domain at the expense of reliable measures). But to be clear: This comparison between the two approaches does not imply that psychometric studies on CPS are impossible or, at least, only possible within the "Ebbinghaus approach". A Brunswikean approach might combine the rigour of psychometric methods with ecological validity - but historically there are only a few examples of successful application of this approach to CPS (see Juslin \& Montgomery, 1999).

\section{FORMAL FRAMEWORKS}

The two formalisms which satisfy the aforementioned requirements-realising different degrees of connectivity and dynamics - are (1) the linear structural equation approach (LSE, see Funke, 1985, 1993; Vollmeyer \& Funke, 1999) and (2) the theory of finite state automata (FSA, see Buchner \& Funke, 1993; Funke $\&$ Buchner, 1992). Both approaches, LSE and FSA, are helpful in modelling the connection between various variables and their effects over time. Whereas the LSE deals with quantitative variables (measured on an interval scale), the FSA is primarily useful for systems consisting of qualitative variables (measured on a nominal scale).

To familiarise the reader with the two approaches, each will be outlined briefly before moving on to the important question of how these frameworks can be used fruitfully in research on human decision making and problem solving. 


\section{Linear Structural Equations (LSE)}

In everyday life, a number of activities require the regulation and control of processes that consist of quantitative variables (e.g., driving a car, controlling a CAD machine). Not only technical but also economic and ecological situations require that we first understand the system before goal-oriented action is possible. In many sciences, systems with quantitative variables are represented successfully by means of the general linear model (see Stevens, 1992). How can such a linear model be used as a tool for analysing decision making and problem solving? The subject is instructed that she or he has to deal with a system that consists of some exogenous and some endogenous variables. The exogenous variables can be directly manipulated by the subject and, thus, can influence the endogenous variables which cannot be manipulated directly. The general task is (a) to find out how the exogenous and endogenous variables are related to each other, and (b) to control the variables in the system so that they reach certain goal values. Normally, these two sub tasks of system identification and system control are separated experimentally as two steps of the whole task (see Funke, 1993). ${ }^{4}$

An example of the basic structure of a simple linear system consisting of four variables is shown in Figure 1 (adopted from Vollmeyer \& Funke, 1999). Instead of labelling the variables semantically, abstract letters are used. A system that contains semantics from biology can be found in Vollmeyer, Burns, and Holyoak (1996). In the example system in Figure 1, A and B represent the exogenous variables which have an effect on the endogenous variables $\mathrm{Y}$ and $\mathrm{Z}$. The numbers on the arrows represent the weight with which the respective exogenous variables affect the endogenous ones. The system is described formally by two equations (one for each endogenous variable):

$$
\begin{gathered}
\mathrm{Y}_{\mathrm{t}+1}=2 \cdot \mathrm{A}_{\mathrm{t}} \\
\mathrm{Z}_{\mathrm{t}+1}=3 \cdot \mathrm{A}_{\mathrm{t}}-2 \cdot \mathrm{B}_{\mathrm{t}}+0,5 \cdot \mathrm{Y}_{\mathrm{t}}+0,9 \cdot \mathrm{Z}_{\mathrm{t}}
\end{gathered}
$$

In these equations, the indices $t$ and $t+1$ represent the actual state of the system which itself goes on in discrete steps (= periods) on the time axis. From equation (1) it emerges that the value of $Y$ at period $t+1$ can be calculated from the value of $A$ at period $t \times 2$. Similar, in equation (2) the value of $Z$ at $t+1$ can be calculated from the exogenous variables $A$ and $B$ at period $t$ (with weight 3 and -2 ), from the value of $\mathrm{Y}$ at that time (weight 0,5 ), and from its own value at period $\mathrm{t} \times 0.9$. Normally, such a system is presented on a screen where all the variables are

\footnotetext{
${ }^{4}$ This separation of exploration and control might reflect the fact that any learning system would naturally lessen the degree of exploration in the course of learning, due to the accumulation of evidence. Thus, this distinction may be more apparent than real, but it is useful for subjects to clarify their task. (See also later sections of the paper.)
} 


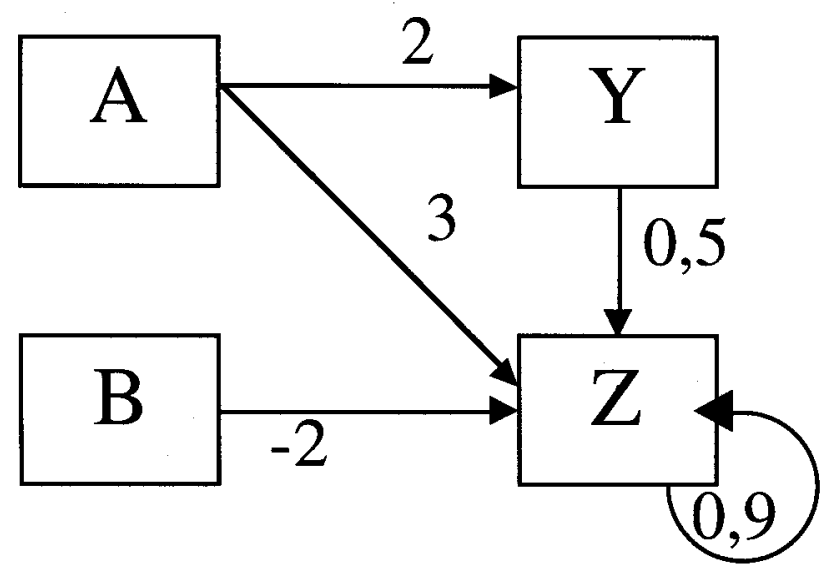

Figure 1. Structure of a simple linear system with two input variables A and B as well as two output variables $\mathrm{Y}$ and $\mathrm{Z}$. Variables are represented as boxes, connections between them are shown by weighted arrows.

shown together with the system's history (for a certain period of time). What is not shown to the subjects is the structure of the system, because this has to be discovered by them during the exploration phase.

In some systems, the endogenous variables have effects on other endogenous ones (in Figure 1, the effect from Y to Z); effects that one might label "indirect" which show up only when manipulating the exogenous variable A. Variable A itself has two effects, one being larger ("main effect" on Z), and one smaller ("side effect" on Y). Also, endogenous variables can influence themselves (shown with variable $\mathrm{Z}$ in the example), thus representing an effect one might call "eigendynamic" because of the constant increase or decrease of this variable independent of other influences. ${ }^{5}$ As the reader might imagine, there are many possible ways to construct linear systems with a full range of effects of the kind just described, thus making identification and control of such systems a difficult problem.

\section{Finite State Automata (FSA)}

Many devices that we use every day, like coffee machines, video and fax machines, cameras, ticket machines, operating systems, any kind of software (and many more, see Weir, 1991), can be characterised on an abstract level by three qualities (see Buchner, 1999): (a) they can only be in a limited (finite) number of states; (b) from a given state they move to the following state either

\footnotetext{
${ }^{5}$ This holds true if and only if the endogenous variable is not equal to zero and the weight is not exactly 1 .
} 
through user input (in the case of software, for example, by pressing a certain key) or through an autonomous process (for instance, in the case of a ticket machine where, after a certain period of no interactions, an automatic reset occurs); (c) normally, an output signal is produced dependent on the user's input and the state reached. Systems with these attributes are represented on a more formal level as finite state automata.

A deterministic finite state automaton (Ashby, 1956; Hopcroft \& Ullmann, 1979; Roberts, 1976; Salomaa, 1985) is defined by a finite set $X$ of input signals, a finite set $\mathrm{Z}$ of states, a finite set $\mathrm{Y}$ of output signals, and two functions (see Hopcroft \& Ullman, 1979, p. 15f): The transition function represents a mapping of $\mathrm{Z} \times \mathrm{X}$ on $\mathrm{Z}$ and determines which state will follow from a given state dependent on the input signal; the result function represents a mapping $\mathrm{Z} \times \mathrm{X}$ on $\mathrm{Y}$ and determines what kind of output signal will follow as a consequence of the input signal. A special case occurs if the output signal depends completely on the state reached and is independent of the input signal. In this case, the result function is replaced by a marker function which connects output signals with states.

FSAs are frequently represented as state-transition matrices or as directed graphs. Each of the two representations illustrate certain aspects of the system in a special way. Table 1, for example, contains the state-transition matrix of a fictitious abstract system whose graphical structure is shown in Figure 2 (for a semantically labelled example, see Buchner \& Funke, 1993).

It can be very useful to view dynamic systems as finite state automata because the important qualities of the system become evident and accessible. In this way, for instance, Funke and Gerdes (1993) not only uncovered failures in the

TABLE 1

State-transition matrix of the system shown in Figure 2

\begin{tabular}{lcc}
\hline & \multicolumn{2}{c}{ Input } \\
\cline { 2 - 3 } States/Output & $x_{1}$ & $x_{2}$ \\
\hline $\mathrm{z}_{0} / \mathrm{y}_{1}$ & $\mathrm{z}_{1}$ & $\mathrm{z}_{0}$ \\
$\mathrm{z}_{1} / \mathrm{y}_{2}$ & $\mathrm{z}_{2}$ & $\mathrm{z}_{2}$ \\
$\mathrm{z}_{2} / \mathrm{y}_{3}$ & $\mathrm{z}_{0}$ & $\mathrm{z}_{2}$ \\
\hline
\end{tabular}

State-transition matrix of a fictitious sytem with three states $\left(\mathrm{z}_{0}, \mathrm{z}_{1}, \mathrm{z}_{2}\right)$ and two input possibilities $\left(\mathrm{x}_{1}, \mathrm{x}_{2}\right)$. Every state has its assigned output sign $\left(\mathrm{y}_{1}, \mathrm{y}_{2}, \mathrm{y}_{3}\right)$. The matrix cells show which state of the system will be reached next depending on the choice of input. For example, if you are in a state $z_{2}$ and choose input $x_{1}$, the resulting state will be $z_{0}$ and the output sign $\mathrm{y}_{1}$ will be emitted. 


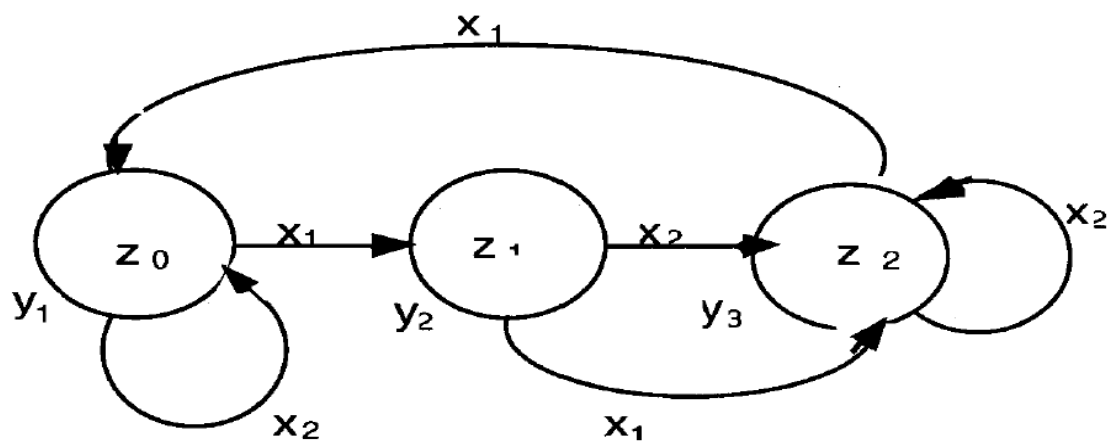

Figure 2. Graphical representation of the finite state automaton with three states $\left(\mathrm{z}_{0}, \mathrm{z}_{1}, \mathrm{z}_{2}\right)$ and two input possibilities $\left(\mathrm{x}_{1}, \mathrm{x}_{2}\right)$ from Table 1 . The outputs sign $\left(\mathrm{y}_{1}, \mathrm{y}_{2}, \mathrm{y}_{3}\right)$ are situated on the left side of the state junctions.

instruction manual of a video recorder, through careful reconstruction of the state transitions of the device as transitions of an finite state automaton and through comparison with the real implemented transitions, but they also improved the presentation of the operation logic in the manual. Buchner, Funke, and Berry (1995) reconstructed the dynamic system "sugar factory" from Berry and Broadbent $(1984,1987)$ as a finite state automaton. As a result of this, they reached a new understanding of frequently reported dissociation phenomena between verbalisable knowledge and control performance. It is argued that "good controllers" observe (as a logical consequence of being good) fewer different state transitions and, consequently, can answer fewer post-task questions about system transitions. Empirical data also show the predicted positive correlation between number of explored state transitions and post-task questionnaire scores. The task analysis in terms of FSA allows a simple explanation of the dissociation effect and needs no assumptions about the involvement of different memory systems.

Further useful aspects of the FSA approach for problem-solving research (assumptions about the learning processes, mental representation, methods of knowledge assessment, systematic construction, and description of a whole class of systems) are presented by Buchner (1999).

\section{TASK DEMANDS AND ASSESSMENT PROCEDURES}

To use the two presented formalisms in research on complex problem solving and decision making, we need to specify in more detail the task requirements, as well as the assessment procedures by which the performance of decision makers and problem solvers can be evaluated. I will start with a description of the two main tasks: knowledge acquisition and knowledge application, illuminating these topics by an example. 
Assume that on your travels you find a ticket machine of a type you have never seen before. What do you have to do in order to get your ticket? Essentially, there are three things to do:

1. You have to find out how the machine works (= knowledge acquisition), that is, you have to find out what input signals (push-buttons, opening for credit card, etc.) are available and what the output signals are (display, card outlay, etc.).

2. You have to discover the price for your journey (= goal finding).

3. You have to control the machine in a way that fulfils your goal (= knowledge application).

Of course, previous experience with these devices might be helpful because of positive transfer, but one has always be aware of potential negative transfer (see Weir \& Alty, 1991).

\section{Task demand 1: Knowledge acquisition}

The term "knowledge acquisition" (system identification) describes a complex learning situation during which the subject has to find out details about the connectivity of the variables and their dynamics. The structural aspects of the system (= connectivity) cannot easily be separated from the dynamic aspects, because the system itself can only be analysed interactively over the time course.

In the LSE situation, this identification problem requires an identification strategy; that is, a certain way of manipulating the exogenous variables so that you can derive from the consequences (in terms of values of the endogenous variables) the causal structure of the system, or at least to come to hypotheses about this structure which could be tested subsequently. Identification of system relation can occur at different levels: (a) as identification of the existence or non-existence of a relation, (b) as specification of a direction, (c) as specification of qualitative aspects of this (either positive or negative) relation, and (d) as the exact quantitative specification of the weight of this relation.

In the FSA situation, the task is similar because the effects of the input signals on the output signals and on the states of the system have to be discovered. Instead of searching for direction, qualitative or quantitative aspects, one has to detect conditions that have to be satisfied in order to make certain state transitions possible.

\section{Task demand 2: Knowledge application}

The term "knowledge application" (system control) describes the situation of applying previously acquired knowledge in order to reach a certain goal state within the system. The goal specifications are normally given by the experimenter. 
In the LSE situation, knowledge application requires two subgoals: first, to transform a given state of the endogenous variables by means of an input vector into the goal state, and second, to keep this goal state on a stable level because in a dynamic system the goal state - once reached-may disappear quickly due to "eigendynamics" (the ability of some variables to influence themselves).

In the FSA situation, the task of knowledge application simply requires finding a path from the initial to the goal state; that is, to find a sequence of input signals that leads to the goal. This task might become fairly difficult if a number of pre-conditions have to be fulfilled in order to allow for a certain critical sequence. (For example, to change the waking time on a clock-radio alarm may require a "set-up sequence" to be passed successfully before a time change is accepted.)

\section{The relationship between knowledge acquisition and knowledge application}

In the preceding section it was assumed that the two processes of knowledge acquisition and knowledge application can be separated from each other. Formally, one can realise this distinction by different instructions to the subject for each of the two tasks. For example, a subject could be instructed to explore the system in a first phase for a certain period of time, in order to control the system in a second phase for certain goal states presented by the experimenter.

However, there is one problem: even under such clear-cut instructions, during the first (exploration) phase subjects could try to reach self-generated goals in order to apply this knowledge without being evaluated. Even during the second (application) phase, subjects can learn about the system because of the feedback they receive from the system for their interventions. One might argue that learning models (such as neural networks) do not separate out knowledge acquisition and knowledge application into distinct stages (or even processes), and that the acquisition of further knowledge is always a result of applying the knowledge that is already accumulated to the new situation. But even though there is truth in this, it has to be acknowledged that after some learning period in a neural network, feedback is removed so that the knowledge application can be tested without contamination by further knowledge acquisition.

Concerning the causal relationship between knowledge acquisition and application, a common assumption holds that acquisition is a necessary and sufficient condition for application. Moreover, a number of older studies (e.g., Berry \& Broadbent, 1984, 1987, 1988) reported dissociation between verbalisable knowledge and control performance. These results have since been interpreted in a somewhat different fashion (cf. Buchner et al., 1995): instead of making the assumption of two different modes of learning (an "implicit" one for 
contingencies and an "explicit" one for hypotheses and rules), Buchner et al. explain the dissociation effects in terms of different degrees of system exploration. Here, different types of knowledge acquisition (in terms of explored state transitions) were made responsible for a specific pattern of response during the application phase.

Also, more recent studies show substantial positive correlations between knowledge acquisition and performance, if subjects are encouraged to acquire knowledge, if they have time, and if an assessment of the acquired knowledge is differentiated enough (e.g., Beckmann, 1994; Beckmann \& Guthke, 1995; Funke, 1993; Kersting, 1999; Müller, 1993; Preußler, 1996, 1998; Sanderson, 1989; Süß, 1999).

\section{What measures can be derived?}

Normally, assessment of cognitive performance uses at least two groups of indicators: solution time and solution quality (see Sternberg, 1982). Both types of indicators neglect the process of working on the task solution. This is one of the disadvantages of conventional IQ testing which is completely result-oriented. The proposed frameworks of LSE and FSA are ideal candidates for the development of process-oriented measures. Nevertheless, solution results can also be evaluated in these paradigms. I will start with the traditional mode of result-oriented assessment before I present some proposals for process-oriented measures.

Result-oriented measures. Starting with the LSE paradigm, there are two general indices to be derived from subjects' interactions with the system: (a) an indicator of the quality of system identification during the first phase of knowledge acquisition, (b) an indicator of the quality of system control during the second phase of knowledge application.

With respect to (a), quality of system identification, a good procedure is the comparison of the real existing causal structure with the assumptions of the subject about the causal relations and their respective weights (the "mental model"). This assessment of structural knowledge, for example by means of causal diagrams drawn by subjects during their exploration, is not free from problems (see Funke, 1991, p. 213) but in a number of studies this procedure has been validated (see Beckmann, 1994; Müller, 1993). The comparison between assumed and existing models can be done by means of a signal-detection analysis. Beckmann (1994) also used a multinomial model (see Batchelder \& Riefer, 1999) to analyse the knowledge structures of his subjects.

With respect to (b), quality of system control, the easiest way is to assess the deviation from the target state by means of a root-mean-squares criterion (RMS). 
This indicator reflects the mean deviation, independent of sign, weighting more heavily those deviations that are further away from the target. ${ }^{6}$

In the case of the FSA paradigm, result-oriented indicators for (a) knowledge acquisition and (b) knowledge application can also be derived in a straightforward way. With respect to (a), the assessment ideally requires a collection of the knowledge about all state transitions. To reduce effort, this could be done by a representative sample of state transitions, which would allow for an estimation of the percentage of correct items. With respect to (b), a good performance should result in using the shortest path between a starting state and a target state. The number of unnecessary steps is thus an indicator of inefficiency in the knowledge application phase.

Process-oriented measures. As stated earlier, the opportunity for processoriented measures appears as one of the advantages of the proposed frameworks. During exploration and control of a system, subjects have to engage in a steady process of knowledge acquisition and knowledge application. This process needs intentions as the steering component, and motivation to keep things running. Therefore, indicators for this process should reveal not only the cognitive activities but also the emotional and motivational forces behind them. Processoriented measures could be an ideal link for the integration of cognitive and volitional theories (Gollwitzer \& Bargh, 1996). Also, those measures could be related to the concept of metacognition, i.e. the self-regulation of cognitive processes (see Flavell, 1979; Weinert \& Kluwe, 1987). However, to be honest, the current status of process-oriented measures is far from optimum. One of the reasons for this sub-optimality might lie in the fact that we are not used to describing subjects' task performance in terms of time-series, trajectories, or distributions of certain measures.

Starting once again with the LSE paradigm, processes during system identification can be observed in terms of strategies used. In order to explore a dynamic system, one needs a kind of experimental design to allow for clear interpretations of the effects that result from certain interventions into the system. Ideally, a "scientific" approach is used which, for example, gives a test input to each of the exogenous variables separately in order to see the consequences within the endogenous variables. If you provide input to all exogenous variables at the same time, the effects cannot easily be disentangled. Also, important hypotheses can be built from zero inputs to all exogenous variables because this procedure reflects the "eigendynamics" most clearly. Besides decisions about the

${ }^{6}$ It should be mentioned that RMS measures tend to produce heavily skewed distributions. Logarithmic transformations help in some cases but not always (see Funke, 1991, p. 212f). 
structure of the system input, one also needs decisions about the dosage or quantity of the interventions. If during the exploration phase one finds that the system can be manipulated without danger, a more intensive intervention would be better because the respective effects would show up more clearly.

If data are available on subjects' hypotheses about the causal relations, it is possible to predict how the mental model changes after certain feedback from the system. The process of identification can be described as hypothesis testing (see Klayman \& Ha, 1987, 1989), and the two-space model from Simon and Lea (1974) allows the separation of the problem space into a rule space and an instance space. In the rule space, all possible rules for that problem are represented, whereas in the instance space, all possible states are represented.

Klahr and Dunbar (1988) started with this two-space model and developed their approach, called "scientific discovery as dual search" (SDDS), for the description of scientific reasoning. Similarly to Simon and Lea (1974) they assumed the existence of an experiment space and a hypothesis space. The latter contains hypotheses about the relationships between variables; the former helps to plan and generate experiments to test the hypotheses. Both spaces interact with each other: activities in the experiment space lead to hypotheses; hypotheses lead to experiments. With the SDDS model, the process during system identification can be described fairly well; also, the model helps to derive process indicators.

Processes during system control should include assessments of (a) how the goal state was reached and (b) what is done to keep the system on the goal state if it was reached. There are no proposals of how to measure either of these.

In the FSA paradigm, processes during the exploration phase can only become visible by a certain sequence of input signals because there are no other means to influence the system. For the evaluation of systematicity of certain sequences, one has to acknowledge that those sequences cannot be judged without knowing the actual state of the system. For example, pressing the same input key three times might be a dull activity in one case where the system gives the output "not possible yet" three times; however, the same three inputs might be very effective in another state of the system, where the three identical inputs move through a selection menu.

Strategic components may also appear if transfer occurs. Normally, in the FSA situation transfer of functions is possible from everyday devices (e.g., option key vs select key), and a good strategy is to test such hypotheses. As usual, a breadth-first strategy can be separated from a depth-first strategy. Also, the degree of systematicity of the exploration can be assessed.

Processes during the FSA control phase find their (result-oriented) manifestations in different degrees of optimality (use of the optimal path from initial to target state) and effectiveness (percentage of effective inputs that lead to system changes compared to the total of inputs). 


\section{CONCLUSION}

The aim of this paper has been to present two classes of dynamic systems, LSE (linear structural equations) and FSA (finite state automata), which can be used in the study of human decision making and problem solving. Starting with an analysis of the main features of complex scenarios, connectivity and dynamics appeared as the two most important aspects from the systems perspective. Both features can be realised easily with LSE as well as with FSA. Further elaboration of the task demands and of possible assessment procedures has shown that research on complex problem solving and naturalistic decision making can profit from these tools, because on the one hand an experimentally driven construction of arbitrary dynamic systems seems possible, which on the other hand does not lose contact with the key task factors, namely dynamics and connectivity. At the same time, within both paradigms psychometrically useful indicators can be derived for the results, as well as for the processes used during identification and control of complex systems.

Concerning the format of the indicators, we have encompassed a broad range: from verbally elicitated data on mental models to purely behaviouristic data based on the pattern of interventions into the system. This aspect is important with respect to theory: the aforementioned "implicit/explicit" distinction relies on different types of data formats (verbalisable, behavioural). The two presented formalisms are open to both kinds of assessment. Therefore, the choice of such a formalism does not necessarily imply a previous decision about specific learning modes. Also, with respect to common approaches to complex problem solving like rule discovery, exemplar learning, or neural networks, the LSE and FSA frameworks are not biased in a particular direction. On the contrary: because of their theoretical "neutrality" they offer the opportunity for a fair comparison between those approaches.

Why should NDM researchers take the "Ebbinghaus" road to the analysis of human judgement in complex situations? As Huber (1995, p. 170f) points out for multi-stage decision making, there are a number of advantages when using such tasks: (a) they are fully understood by the researcher, (b) it is possible to derive an optimal strategy and, thus, to compare subjects' activities with the optimal procedures, (c) hypotheses about the effects of variations of system attributes are easy to formulate, (d) the interaction between person and situation can be investigated more easily, (e) the abstract task can easily be transformed into different semantic embeddings (problem isomorphs) to look for context effects, and (f) simple tasks can be made more and more complex in order to attain more and more realism. In general, the advantages are those that help researchers to test their hypotheses experimentally.

What are the disadvantages of this approach? First, a certain loss of fidelity of the scenarios occurs due to the restrictions of the formalisms. Even if one tries to combine both approaches, LSE and FSA, into a hybrid systems approach, certain 
well-known system effects (e.g., deterministic chaos; see Ward \& West, 1998) cannot be realised within the (combined) formalisms. Second, if the number of variables in such a system goes beyond 20-30, the utility of these tools suffers due to the increasing complexity for the researcher. Third, this approach normally starts with the construction of a certain formal system by trying to make it look like a realistic scenario, instead of starting with a real-life problem that is later reconstructed in terms of the formalisms.

To conclude: Even if the presented tools are limited in their flexibility and their utility I think the processes that occur during decision making and problem solving will become more easily accessible, and hypothesis formation about these processes as well as experimentation with system attributes will be stimulated. Also, the comparison between different scenarios will become easier. At the same time, important features like connectivity and dynamics, which really make a problem difficult, are retained within the tasks of system identification and system control. As Rigas and Brehmer (1999, p. 62) pointed out: we need new forms of tests aimed at the more complex processes going on during subjects' problem solving within microworlds. Perhaps FSA and LSE tasks can be seen as examples of such tests.

\section{REFERENCES}

Ashby, W.R. (1956). An introduction to cybernetics. London: Chapman \& Hall.

Batchelder, W.H., \& Riefer, D.M. (1999). Theoretical and empirical review of multinomial processing tree modeling. Psychonomic Bulletin \& Review, 6, 57-86.

Beckmann, J.F. (1994). Lernen und komplexes Problemlösen. Ein Beitrag zur Konstruktvalidierung von Lerntests [Learning and complex problem solving. A contribution to the validation of learning tests]. Bonn: Holos.

Beckmann, J.F., \& Guthke, J. (1995). Complex problem solving, intelligence, and learning ability. In P.A. Frensch \& J. Funke (Eds.), Complex problem solving: The European perspective (pp. 177-200). Hillsdale, NJ: Lawrence Erlbaum Associates Inc.

Berry, D.C., \& Broadbent, D.E. (1984). On the relationship between task performance and associated verbalizable knowledge. Quarterly Journal of Experimental Psychology, 36A, 209231.

Berry, D.C., \& Broadbent, D.E. (1987). The combination of explicit and implicit learning processes in task control. Psychological Research, 49, 7-15.

Berry, D.C., \& Broadbent, D.E. (1988). Interactive tasks and the implicit-explicit distinction. British Journal of Psychology, 79, 251-272.

Berry, D.C., \& Broadbent, D.E. (1995). Implicit learning in the control of complex systems. In P.A. Frensch \& J. Funke (Eds.), Complex problem solving: The European perspective (pp. 131-150). Hillsdale, NJ: Lawrence Erlbaum Associates Inc.

Blessing, S.B., \& Ross, B.H. (1996). Content effects in problem categorization and problem solving. Journal of Experimental Psychology: Learning, Memory, and Cognition, 22, 792-810.

Brehmer, B., \& Dörner, D. (1993). Experiments with computer-simulated microworlds: Escaping both the narrow straits of the laboratory and the deep blue sea of the field study. Computers in Human Behavior, 9, 171-184.

Brehmer, B., Leplat, J., \& Rasmussen, J. (1991). Use of simulation in the study of complex 
decision making. In J. Rasmussen, B. Brehmer, \& J. Leplat (Eds.), Distributed decision making: Cognitive models for cooperative work (pp. 373-386). New York: Wiley.

Broadbent, D.E. (1977). Levels, hierarchies, and the locus of control. Quarterly Journal of Experimental Psychology, 29, 181-201.

Broadbent, D., \& Aston, B. (1978). Human control of a simulated economic system. Ergonomics, $21,1035-1043$.

Broadbent, D.E., Fitzgerald, P., \& Broadbent, M.H.P. (1986). Implicit and explicit knowledge in the control of complex systems. British Journal of Psychology, 17, 33-50.

Buchner, A. (1995). Basic topics and approaches to the study of complex problem solving. In P.A. Frensch \& J. Funke (Eds.), Complex problem solving: The European perspective (pp. 27-63). Hillsdale, NJ: Lawrence Erlbaum Associates Inc.

Buchner, A. (1999). Komplexes Problemlösen vor dem Hintergrund der Theorie finiter Automaten [Complex problem solving seen from the theory of finite state automata]. Psychologische Rundschau, 50, 206-212.

Buchner, A., \& Funke, J. (1993). Finite state automata: Dynamic task environments in problem solving research. Quarterly Journal of Experimental Psychology, 46A, 83-118.

Buchner, A., Funke, L, \& Berry, D.C. (1995). Negative correlations between control performance and verbalizable knowledge: Indicators for implicit learning in process control tasks? Quarterly Journal of Experimental Psychology, 48A, 166-187.

Casti, J. (1979). Connectivity, complexity, and catastrophe in large-scale systems. New York: Wiley.

Dörner, D. (1980). On the difficulty people have in dealing with complexity. Simulation \& Games, $11,87-106$.

Dörner, D. (1986). Diagnostik der operativen Intelligenz [Assessment of operative intelligence]. Diagnostica, 32, 290-308.

Dörner, D. (1987). On the difficulties people have in dealing with complexity. In J. Rasmussen, K. Duncan, \& J. Leplat (Eds.), New technology and human error (pp. 97-109). Chichester, UK: Wiley.

Dörner, D. (1992). Über die Philosophie der Verwendung von Mikrowelten oder "Computerszenarios" in der psychologischen Forschung [On the proper use of microworlds or "computer scenarios" in psychological research]. In H. Gundlach (Ed.), Psychologische Forschung und Methode: Das Versprechen des Experiments. Festschrift für Werner Traxel (pp. 53-87). Passau, Germany: Passavia Universitäts-Verlag.

Dörner, D. (1996). The logic of failure. Recognizing and avoiding error in complex situations. Reading, MA: Addison-Wesley.

Dörner, D., \& Kreuzig, H.W. (1983). Problemlösefähigkeit und Intelligenz [Problem solving ability and intelligence]. Psychologische Rundschau, 34, 185-192.

Dörner, D., Kreuzig, H.W., Reither, F., \& Stäudel, T. (1983). Lohhausen. Vom Unigang mit Unbestimmtheit und Komplexität [Lohhausen. On dealing with uncertainty and complexity]. Bern: Huber.

Dörner, D., Schaub, H., \& Strohschneider, S. (1999). Komplexes Problemlösen-Königsweg der Theoretischen Psychologie? [Complex problem solving-Via regia of theoretical psychology?]. Psychologische Rundschau, 50, 198-205.

Dörner, D., \& Wearing, A. (1995). Complex problem solving: Toward a (computersimulated) theory. In P.A. Frensch \& J. Funke (Eds.), Complex problem solving: The European perspective (pp. 65-99). Hillsdale, NJ: Lawrence Erlbaum Associates Inc.

Flavell, J.H. (1979). Metacognition and cognitive monitoring. A new area of cognitivedevelopmental inquiry. American Psychologist, 34, 906-911.

Frensch, P.A. (1998). One concept, multiple meanings: On how to define the concept of implicit learning. In M.A. Stadler \& P.A. Frensch (Eds.), Handbook of implicit learning (pp. 47-104). Thousand Oaks, CA: Sage. 
Frensch, P.A., \& Funke, J. (Eds.) (1995). Complex problem solving: The European perspective. Hillsdale, NJ: Lawrence Erlbaum Associates Inc.

Funke, J. (1984). Diagnose der westdeutschen Problemlöseforschung in Form einiger Thesen [Assessment of West German problem solving research]. Sprache \& Kognition, 3, 159-172.

Funke, J. (1985). Steuerung dynamischer Systeme durch Aufbau und Anwendung subjektiver Kausalmodelle [Control of dynamic systems by building up and using subjective causal models]. Zeitschrift für Psychologie, 193, 435-457.

Funke, J. (1988). Using simulation to study complex problem solving: A review of studies in the FRG. Simulation \& Games, 19, 277-303.

Funke, J. (1990). Systemmerkmale als Determinanten des Umgangs mit dynamischen Systemen [System features as determinants of dynamic task environments]. Sprache \& Kognition, 9, 143-154.

Funke, J. (1991). Solving complex problems: Exploration and control of complex systems. In R.J. Sternberg \& P.A. Frensch (Eds.), Complex problem solving: Principles and mechanisms (pp. 185-222). Hillsdale, NJ: Lawrence Erlbaum Associates Inc.

Funke, J. (1993). Microworlds based on linear equation systems: A new approach to complex problem solving and experimental results. In G. Strube \& K.-F. Wender (Eds.), The cognitive psychology of knowledge (pp. 313-330). Amsterdam: Elsevier.

Funke, J. (1995). Experimental research on complex problem solving. In P.A. Frensch \& J. Funke (Eds.), Complex problem solving: The European perspective (pp. 243-268). Hillsdale, NJ: Lawrence Erlbaum Associates Inc.

Funke, J., \& Buchner, A. (1992). Finite Automaten als Instrumente für die Analyse von wissensgeleiteten Problemlöseprozessen: Vorstellung eines neuen Untersuchungsparadigmas [Finite-state automata as instruments for the analysis of knowledge-based problem solving: Introducing a new research paradigm]. Sprache \& Kognition, 11, 27-37.

Funke, J., \& Gerdes, H. (1993). Manuale für Videorekorder: Auswahl von Textinhalten unter Verwendung der Theorie endlicher Automaten [Manuals for video recorders: Selecting text on the basis of finite state automata theory]. Zeitschrift für Arbeitswissenschaft, 47, 44-49.

Gardner, P.H., \& Berry, D.C. (1995). The effect of different forms of advice on the control of a simulated complex system. Applied Cognitive Psychology, 9 (Special Issue), S55-S79.

Gollwitzer, P.M., \& Bargh, J.A. (Eds.) (1996). The psychology of action: Linking cognition and motivation to behavior. New York: Guilford Press.

Hayes, N.A., \& Broadbent, D.E. (1988). Two modes of learning for interactive tasks. Cognition, $28,249-276$.

Hays, R.T., \& Singer, M.J. (1989). Simulation fidelity in training system design. Bridging the gap between reality and training. New York: Springer.

Hesse, F.W. (1982). Effekte des semantischen Kontexts auf die Bearbeitung komplexer Probleme [Effects of semantic context on complex problem solving]. Zeitschrift für Experimentelle und Angewandte Psychologie, 29, 62-91.

Hesse, F.W., Kauer, G., \& Spies, K. (1997). Effects of emotion-related surface similarity in analogical problem solving. American Journal of Psychology, 110, 357-383.

Hopcroft, J.E., \& Ullmann, S.D. (1979). Introduction to automata theory, languages, and computation. Reading, MA: Addison-Wesley.

Huber, O. (1995). Complex problem solving as multistage decision making. In P.A. Frensch \& J. Funke (Eds.), Complex problem solving: The European perspective (pp. 151-173). Hillsdale, NJ: Lawrence Erlbaum Associates Inc.

Hussy, W. (1984). Denkpsychologie. Ein Lehrbuch. Band 1: Geschichte, Begriffs- und Problemlöseforschung, Intelligenz [Psychology of thinking. A primer. Volume 1: History, concept formation and problem solving, intelligence]. Stuttgart: Kohlhammer.

Juslin, P., \& Montgomery, H. (Eds.) (1999). Judgement and decision making: Neo-Brunswikean and process-tracing approaches. Hillsdale, NJ: Lawrence Erlbaum Associates Inc. 
Kersting, M. (1999). Diagnostik und Personalauswahl mit computergestützten Problemlöseszenarien? Zur Kriteriumsvalidität von Problemlöseszenarien und Intelligenztests [Assessment and personnel selection with computer-simulated problem-solving scenarios? On the validity of problem-solving scenarios and intelligence tests]. Göttingen: Hogrefe.

Klahr, D., \& Dunbar, K. (1988). Dual space search during scientific reasoning. Cognitive Science, $12,1-48$.

Klayman, J., \& Ha, Y.-W. (1987). Confirmation, disconfirmation, and information in hypothesis testing. Psychological Review, 94, 211-228.

Klayman, J., \& Ha, Y.-W. (1989). Hypothesis testing in rule discovery: Strategy, structure, and content. Journal of Experimental Psychology: Learning, Memory, and Cognition, 15, 596-604.

Klein, G. (1997). The current status of the naturalistic decision making framework. In R.H. Flin, E. Salas, M. Strub, \& L. Martin (Eds.), Decision making under stress. Emerging theories and applications (pp. 11-28). Aldershot, UK: Ashgate.

Kotkamp, U. (1999). Elementares und komplexes Problemlösen: Über Invarianzeigenschaften von Denkprozessen [Elementary and complex problem solving: About invariance features of thinking processes]. Lengerich: Pabst.

Kotovsky, K., \& Fallside, D. (1989). Representation and transfer in problem solving. In D. Klahr \& K. Kotovsky (Eds.), Complex information processes (pp. 69-108). Hillsdale, NJ: Lawrence Erlbaum Associates Inc.

Luc, F., Marescaux, P.-J., \& Karnas, G. (1989). Modes d'apprentissage implicite et explicite dans une tâche de contrôle dynamique: Influence des traits de surface du système et d'une information donnée dans la consigne. Année Psychologique, 89, 489-512.

Moray, N., Lootsteen, P., \& Pajak, J. (1986). Acquisition of process control skills. IEEE Transactions on Systems, Man, and Cybernetics, SMC-16, 497-504.

Müller, H. (1993). Komplexes Problemlösen: Reliabilität und Wissen [Complex problem solving: Reliability and knowledge]. Bonn: Holos.

Novick, L.R. (1988). Analogical transfer, problem similarity and expertise. Journal of Experimental Psychology: Learning, Memory, and Cognition, 14, 510-520.

Preußler, W. (1996). Zur Rolle expliziten und impliziten Wissens bei der Steuerung dynamischer Systeme. [On the role of explicit and implicit knowledge in controlling dynamic systems]. Zeitschrift für Experimentelle Psychologie, 43, 399-434.

Preußler, W. (1997). Effekte des Kontexts auf den Wissenserwerb bei der Steuerung eines dynamischen Systems [Effects of context on the acquisition of knowledge in controlling a dynamic system]. Sprache \& Kognition, 16, 48-59.

Preußler, W. (1998). Strukturwissen als Voraussetzung für die Steuerung komplexer dynamischer Systeme [Structural knowledge as a precondition of controlling complex dynamic systems]. Zeitschrift für Experimentelle Psychologie, 45, 218-240.

Putz-Osterloh, W. (1993). Strategies for knowledge acquisition and transfer of knowledge in dynamic tasks. In G. Strube \& K.-F. Wender (Eds.), The cognitive psychology of knowledge (pp. 331-350). Amsterdam: Elsevier.

Putz-Osterloh, W., \& Lemme, M. (1987). Knowledge and its intelligent application to problem solving. The German Journal of Psychology, 11, 286-303.

Rigas, G., \& Brehmer, B. (1999). Mental processes in intelligence tests and dynamic decision making tasks. In P. Juslin \& H. Montgomery (Eds.), Judgement and decision making: Neo-Brunswikean and process-tracing approaches (pp. 45-65). Hillsdale, NJ: Lawrence Erlbaum Associates Inc.

Roberts, F.S. (1976). Discrete mathematical models. With applications to social, biological, and environmental problems. Englewood Cliffs, NJ: Prentice-Hall.

Salomaa, A. (1985). Computation and automata. Cambridge: Cambridge University Press.

Sanderson, P.M. (1989). Verbalizable knowledge and skilled task performance: Association, dissociation, and mental models. Journal of Experimental Psychology: Learning, Memory, and 
Cognition, 15, 729-747.

Simon, H.A., \& Lea, G. (1974). Problem solving and rule induction: A unified view. In L.W. Gregg (Ed.), Knowledge and cognition (pp. 105-127). Hillsdale, NJ: Lawrence Erlbaum Associates Inc.

Stadler, M.A., \& Frensch, P.A. (Eds.) (1998). Handbook of implicit learning. Thousand Oaks, CA: Sage.

Sternberg, R.J. (1982). Reasoning, problem solving, and intelligence. In R.J. Sternberg (Ed.), Handbook of human intelligence (pp. 225-307). Cambridge: Cambridge University Press.

Sternberg, R.J. (1995). Expertise in complex problem solving: A comparison of alternative conceptions. In P.A. Frensch \& J. Funke (Eds.), Complex problem solving: The European perspective (pp. 295-321). Hillsdale, NJ: Lawrence Erlbaum Associates Inc.

Sternberg, R.L., \& Frensch P.A. (Eds.) (1991). Complex problem solving: Principles and mechanisms. Hillsdale, NJ: Lawrence Erlbaum Associates Inc.

Stevens, J. (1992). Applied multivariate statistics for the social sciences. (2nd ed.). Hillsdale, NJ: Lawrence Erlbaum Associates Inc.

Strauß, B. (1993). Konfundierungen beim Komplexen Problemlösen. Zum Einfluß des Anteils der richtigen Lösungen (ArL) auf das Problemlöseverhalten in komplexen Situationen [Confounds in complex problem solving. On the influence of the degree of correct solutions on problem solving in complex situations]. Bonn: Holos.

Strohschneider, S. (1991). Kein System von Systemen! Kommentar zu dem Aufsatz "Systemmerkmale als Determinanten des Umgangs mit dynamischen Systemen" von Joachim Funke [No system of systems! Reply to the paper "System features as determinants of behavior in dynamic task environments" by Joachim Funke]. Sprache \& Kognition, 10, 109-113.

Süß, H.-M. (1999). Intelligenz und komplexes Problemlösen [Test intelligence and complex problem solving]. Psychologische Rundschau, 50, 220-228.

van Gelder, T. (1998). The dynamical hypothesis in cognitive science. Behavioral and Brain Sciences, 21, 615-665.

Vollmeyer, R., Burns, B.D., \& Holyoak, K.J. (1996). The impact of goal specificity on strategy use and the acquisition of problem structure. Cognitive Science, 20, 75-100.

Vollmeyer, R., \& Funke, J. (1999). Personen- und Aufgabenmerkmale beim komplexen Problemlösen [Person and task effects within complex problem solving]. Psychologische Rundschau, 50, 213-219.

Wagenaar, W.A., Keren, G., \& Lichtenstein, S. (1988). Islanders and hostages: Deep and surface structures of decision problems. Acta Psychologica, 67, 175-189.

Wallach, D. (1998). Komplexe Regelungsprozesse. Eine kognitionswissenschaftliche Analyse [Complex control processes. A cognitive science analysis]. Wiesbaden: Deutscher Universitäts-Verlag.

Ward, L.M., \& West, R.L. (1998). Modeling human chaotic behavior: Nonlinear forecasting analysis of logistic iteration. Nonlinear Dynamics, Psychology, and Life Sciences, 2, 261-282.

Weinert, F.E., \& Kluwe, R.H. (Eds.) (1987). Metacognition, motivation, and understanding. Hillsdale, NJ: Lawrence Erlbaum Associates Inc.

Weir, G.R.S. (1991). Living with complex interactive systems. In G.R.S. Weir, \& J.L. Alty (Eds.), Human computer interaction and complex systems (pp. 1-21). New York: Academic Press.

Weir, G.R.S., \& Alty, J.L. (Eds.) (1991). Human computer interaction and complex systems. New York: Academic Press.

Zsambok, C.E. (1997). Naturalistic decision making: Where are we now? In C.E. Zsambok \& G.A. Klein (Eds.), Naturalistic decision making (pp. 3-16). Mahwah, NJ: Lawrence Erlbaum Associates Inc. 